Methods: Patients with SpA diagnosed according to the assessment of Spondyloarthritis International Society criteria were included in this retrospective cross-sectional study.

The modified Stoke Ankylosing Spondylitis Spine Score (mSASSS) and the Bath Ankylosing Spondylitis Radiology Index-spine (BASRI-s) were used to assess the radiographic involvement of the spine.

The sacroiliac joints were scored according to the modified New York criteria.

Radiological hip involvement was scored using the Bath Ankylosing Spondylitis Radiology Index hip (BASRI-h).

Patients were divided into two groups: G0 including patients without hip involvement and G1 patients with hip involvement.

Results: We included 112 patients with a sex ratio of 2.4. The average SpA symptom duration was $9.33 \pm 8.93$ years. The diagnostic delay was $42.92 \pm 52$ months.

Radiographic hip involvement was noted in $39.28 \%$ of cases. It was bilateral in 31 patients $(70.4 \%)$. The total number of coxitis was 75 . Severe and moderate hip involvement (BASRI- $\mathrm{h} \geq 3$ ) affected 21 hips. The most common radiographic pattern was early coxitis $(n=31,41.3 \%)$ followed by the destructive form $(n=22$, $29.3 \%$, mimicking-osteoarthritis form $(n=15,20 \%)$, condensing form $(n=5,6.6 \%)$ and ankylosing form $(n=2,2 \%)$.

Radiographic sacroiliitis was noted in $75.8 \%$ of patients. It was bilateral in $91.7 \%$ of cases. Among the 161 sacroiliac joints fulfilling the m-New-york criteria, 32.9\% had grade 4 and $37.2 \%$ had grade 3 .

The mean mSASSS was $10.26 \pm 15$. The mean BASRI-t, BASRI-C, and BASRI-L were $3.99 \pm 2.9,0.89 \pm 1.3$, and $1.1 \pm 1.3$ respectively.

Radiographic sacroiliitis was more common in patients with hip involvement (G1) (90.9\% vs 68.2\%, $\mathrm{p}=0.00)$. Patients in $\mathrm{G} 1$ had higher mSASSS $(15.78 \pm 18.24$ vs $6.29 \pm 11.85, p=0.01)$, BASRI-L $(1.73 \pm 1.46$ vs $0.75 \pm 1.131, p=0.009)$, and BASRI-s $\left(5.46 \pm 3.02\right.$ vs $\left.3.19 \pm 2.46, p<10^{-3}\right)$ than patients in $\mathrm{G} 2$. There was no significant difference between the two groups regarding the BASRI-C

Multivariable analysis revealed that radiographic sacroiliitis was associated with hip involvement $(\mathrm{OR}=14.81,95 \%,[1.1-198], \mathrm{p}=0.042)$

When comparing patients with severe and moderate hip involvement (BASRI-h $\geq$ 3) and those with mild involvement, we didn't find significant differences regarding BASRIs, BASR-L, BASRI-c, mSASSS, and sacroiliac involvement.

Conclusion: As reported in previous studies [1], we concluded that structural axial lesions were higher in patients with coxitis. Structural damage to the sacroiliac joint in SpA was predictive of hip involvement.

We suggest that sacroiliitis, spinal and hip involvement are part of the same spectrum.

References:

11] Chen H-A, Chen C-H, Liao H-T, Lin Y-J, Chen P-C, Chen W-S, et al. Factors associated with radiographic spinal involvement and hip involvement in ankylosing spondylitis. Semin Arthritis Rheum. 2011;40 (6):552-8

Disclosure of Interests: None declared

DOI: 10.1136/annrheumdis-2020-eular.4321

\section{AB0725 1 FACTORS ASSOCIATED WITH RADIOGRAPHIC SPINAL INVOLVEMENT IN SPONDYLOARTHRITIS}

M. Slouma ${ }^{1}$, S. Rahmouni ${ }^{1}$, R. Dhahri ${ }^{1}$, I. Gharsallah ${ }^{1}$, N. Boussetta ${ }^{1}$, H. Gueddich ${ }^{1}$, F. Ajili ${ }^{1}$, L. Metoui ${ }^{1}$, B. Louzir ${ }^{1} .{ }^{1}$ Military Hospital of Instruction of Tunis, Department of Internal Medicine, Tunis, Tunisia

Background: Spondyloarthritis $(\mathrm{SpA})$ is characterized by significant radiographic changes in the spine. The structural spine damage can be assessed using several scorings such as the Bath AS Radiology Index (BASRI) and the modified Stoke Ankylosing Spondylitis Spine Score (mSASSS).

Objectives: We aimed to identify factors associated with structural damage in the spine using these scores.

Methods: We conducted a cross-sectional study including patients with SpA diagnosed according to the assessment of Spondyloarthritis International Society criteria.

To assess the radiographic involvement of the spine, we used the mSASSS, the BASRI-spine (BASRI-S), the BASRI-lumber (BASRI-L) and the BASRI-cervical (BASRI-C)

Disease activity was assessed using the BASDAI and ASDAS-CRP.

Results: Among the 112 patients, $72.32 \%$ were men. The mean age was $43.78 \pm$ 12,91 years. The mean age at diagnosis was $37.8 \pm 13.45$ years. The diagnostic delay of $37,8 \pm 46$ months.

Forty-nine patients were smockers (43.8\%).

The mean BASDAI score and ASDAS-CRP score were $4.04 \pm 1.99$ and $3.30 \pm$ 0.87 .

The mean ESR and CRP were $36.21 \pm 27(\mathrm{~mm} / \mathrm{H})$ and $31.28 \pm 47.25 \mathrm{mg} / \mathrm{L}$

The mean BASRI-S was $3,99 \pm 21,96$ and the mean mSASSS was $10,26 \pm 15,41$. Twenty-five patients $(22.3 \%)$ had non-radiographic axial SpA

Men had higher BARSI-L (1.36 vs $0.7, p=0.045)$ and BASRI-S (4.3 vs 3.09; $\mathrm{p}=0.047$ ) than women.
Moreover, smokers' patients had higher mSASSS (14.07 vs 7.02; $p=0.031$ ), BASRI-C (1.23 vs $0.62 ; p=0.031)$, and BASRI-S (4.82 vs 3.35; $p=0.009)$ than nonsmokers' patients.

A positive correlation was noted between age and BASRI-C ( $r=0.260, p=0.012)$. There was no correlation between age at the onset of SpA and structural spine damage.

We found a positive correlation between disease duration and the following scores: BASRI-C ( $r=0.245, p=0.018)$ and BASRI-S $(r=0.274, p=0.003)$

Patients with non-radiographic axial SpA had lower mSASSS (4.05 vs 12.14 $p=0.034)$, BASRI-s (1.2 vs $4.9 ; p<10-3)$, and BASRI-L (0.42 vs $1.4 ; p=0.003)$ than patients with radiographic axial SpA.

There was no correlation between the radiographic index and BASDAI and ASDAS-CRP.

Conclusion: We confirmed previous observations that male gender, smoking and disease duration are associated with structural damage in the spine [1]

However, CRP and other inflammatory biomarkers were not associated with radiographic evidence of spine involvement.

As observed in previous studies, the radiographic spine damage did not correlate with disease activity (BASDAI) [1].

References:

[1] Sari I, Haroon N. Radiographic Progression in Ankylosing Spondylitis: From Prognostication to Disease Modification. Curr Rheumatol Rep. 2018 Nov 8;20(12):82.

Disclosure of Interests: None declared

DOI: 10.1136/annrheumdis-2020-eular.4372

\section{AB0726 1 CHOROIDAL THICKNESS IS A BIOMARKER AND CAN PREDICT THE RESPONSE TO TREATMENT IN ANKYLOSING SPONDYLITIS}

M. Steiner ${ }^{1}$, M. D. M. Esteban-Ortega ${ }^{1}$, I. Thuissard-Vasallo ${ }^{2}$, I. García-Lozano ${ }^{1}$, J. García $^{3}$, E. Perez-Blazquez ${ }^{3}$, J. Sambricio ${ }^{3}$, Á. García-Aparicio ${ }^{4}$, B. F. CascoSilva $^{4}$, J. Sanz ${ }^{5}$, N. Valdés-Sanz ${ }^{5}$, C. Fernandez-Espartero ${ }^{6}$, T. Díaz-Valle ${ }^{6}$, M. Gurrea-Almela ${ }^{6}$, J. Fernández-Leroy ${ }^{7}$, M. Gómez-Resa ${ }^{8}$, E. Pato ${ }^{9}$, D. Díaz Valle $^{9}$, R. Méndez-Fernández ${ }^{9}$, M. T. Navio Marco ${ }^{10}$, S. Muñoz-Fernández ${ }^{1}$. ${ }^{1}$ Hospital Universitario Infanta Sofía, Madrid, Spain; ${ }^{2}$ Universidad Europea, Madrid, Spain; ${ }^{3}$ Hospital Universitario 12 de Octubre, Madrid, Spain; ${ }^{4}$ Hospital Universitario Virgen de la Salud, Toledo, Spain; ${ }^{5}$ Hospital Universitario de Majadahonda, Madrid, Spain; ${ }^{6}$ Hospital Universitario de Móstoles, Madrid, Spain: ${ }^{7}$ Hospital Universitario Son Espases, Madrid, Spain; ${ }^{8}$ Hospital Universitario Son Espases, Palma de Mallorca, Spain; ${ }^{9}$ Hospital Clínico San Carlos, Madrid, Spain; ${ }^{10}$ Hospital Universitario Infanta Leonor, Madrid, Spain

Background: Choroidal thickness (CT) has been proposed and evaluated as a potential marker of systemic inflammation associated with inflammatory diseases as Ankylosing spondylitis (AS). Patients with active AS have a thicker choroid than healthy subjects, regardless of eye inflammation. The evolution of choroid after treatment is poorly known.

Objectives: This study evaluates the CT of patients with severe AS disease activity before and after six months of biological therapy.

Methods: This prospective multicenter study evaluates the CT in 44 patients with high AS disease activity, naïve for biological treatment, and no history of eye inflammation before and after six months of biological therapy, aged from 18 to 65 years. The correlations between the CT and C-reactive protein (CRP) with the disease activity indices and scales as Bath Ankylosing Spondylitis Disease Activity Index (BASDAI), night pain and Patient Global Assessment (PGA) were calculated at baseline and after six months of biological therapy. The concordance between the CT and CRP was determined. Finally, we assessed potential predictors of response to treatment. Clinically important improvement was defined as a decrease in ASDAS score $\geq 1.1$ points

Results: Globally, 44 eyes of 44 patients aged between 18-65 years were included in the study, $12(27 \%)$ women. The biological treatments prescribed were: Adalimumab 13 (29.5\%), Certolizumab 9 (20.5\%), Secukinumab 10 (20\%), Etanercept 8 (18\%), Infliximab $3(6.8 \%)$, and Golimumab $1(2.2 \%)$.

Mean CT values were significantly higher at baseline than after six months of treatment (baseline 355.28 $\pm 80.46 \mu \mathrm{m} ; 6$ months, 341.26 $\pm 81.06 \mu \mathrm{m})(p<0.001)$. CT decreased both in patients on biological treatment without effect in eye (Secukinumab and Etanecept; $p=0.024$ ) and in patients on treatment with effect in eye (other; $p=0.005$ ). Also, CRP, BASDAl, night pain and PGA decreased after six months of treatment $((p<0.001, p<0.001, p<0.001, p<0.001)$. We found a $95 \%$ concordance between CT and CRP at baseline and 6 months.

Multivariable analysis showed that clinically important improvement was associated with higher CT and age as independent factors (OR 0.97, CI95\% 0.91-0.93; $\mathrm{p}=0.009$, and OR 0.81 , C195\% 0.7-0.95; $\mathrm{p}=0.005)$. Clinically important improvement was associated with basal CT $>374 \mu \mathrm{m}$ (sensitivity $78 \%$, [Cl 95\% 60-90], specificity $78 \%$ [Cl $95 \% 52-92]$, area under the curve of ROC, 0.70 , likelihood ratio 3.6$)$.

Conclusion: CT decreased significantly after six months of biological treatment. CT and CPR had a 95\% concordance. A high CT is associated with risk of failure 